\title{
Selecting euploid embryo for transfer by preimplantation genetic testing for aneuploidy improved clinical outcomes in patients with advanced maternal age
}

\author{
Le Thi Bich Phuong1,2, Vo Nguyen Thuc 1,2, Pham Thieu Quan ${ }^{1,2}$, Le Hoang Anh ${ }^{1,2}$, Dang Quang Vinh ${ }^{1,2}$, \\ Nguyen Thi Thuong Huyen ${ }^{3, *}$
}

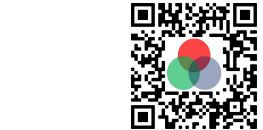

Use your smartphone to scan this QR code and download this article

${ }^{1}$ IVFMD Phu Nhuan, My Duc Phu Nhuan Hospital, Ho Chi Minh City, Viet Nam

${ }^{2}$ HOPE Research center, Ho Chi Minh City, Viet Nam

${ }^{3}$ Department of Biology, Ho Chi Minh City University of Education, Viet Nam

Correspondence

Nguyen Thi Thuong Huyen, Department of Biology, Ho Chi Minh City University of Education, Viet Nam

Email: huyenntth@hcmue.edu.vn

History

- Received: Oct 19, 2019

- Accepted: Dec 23, 2019

- Published: Dec 31, 2019

DOI : 10.15419/bmrat.v6i12.581

\section{Check for updates}

\section{Copyright}

(c) Biomedpress. This is an openaccess article distributed under the terms of the Creative Commons Attribution 4.0 International license.

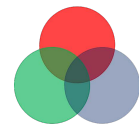

BioMedPress

The Open Access Publisher

\begin{abstract}
Objectives: This study aimed to investigate whether selecting euploid embryos by preimplantation genetic testing for aneuploidy (PGT-A) can improve the clinical outcomes in patients with advanced maternal age. Hence, it provides evidence about the role of PGT-A in the treatment for patients with advanced maternal age in Vietnam. Methods: This is a retrospective cohort study, conducted at IVFMD, My Duc Hospital, Vietnam, from March 2017 to March 2019. There were 244 patients taking preimplantation genetic testing for aneuploidy (PGT-A group). Biopsy was performed at the blastocyst stage. On the day of biopsy, about 5-6 trophectoderm cells were collected and sent to analysis, while the remaining was individually vitrified to be used for embryo transfer to the patient. When patients had PGT-A, the clinician consulted and indicated the euploid embryo for frozen embryo transfer cycle. The ongoing pregnancy rate was compared with the group of patients who only performed blastocyst transfer (non-PGT-A group). Other outcomes, such as the average number of transferred embryos, clinical pregnancy rate, implantation rate, miscarriage rate and multiple pregnancy rate, were also compared between the two groups. Results: In the total of 493 patients fulfilled the inclusion criteria, there were 244 patients in PGT-A group and 249 patients in non-PGT-A group. The patient characteristics of the two groups were similar $(p>0.05)$. A total of 816 blastocysts were biopsied and 315 (38.6\%) of these were aneuploidy. The ongoing pregnancy rate of PGT-A group was significantly higher than non-PGT-A group (43.9\% vs. 32.1\%, $p=0.01$ ). Moreover, mean number of transferred embryos and multiple pregnancy rate of PGT-A group was lower than non-PGT-A group (1.3 vs. $2, \mathrm{p}<0.001 ; 5.7 \%$ vs. $12 \%, \mathrm{p}<0.001$, respectively). Conclusions: In patients with advanced maternal age, the transfer of euploidy embryos selected by PGT-A improved the ongoing pregnancy rate and reduced the number of transferred embryos and multiple pregnancy rate. Therefore, this group of patients may benefit from PGT-A.
\end{abstract}

Key words: aneuploidy, advanced maternal age, blastocyst biopsy, embryo, euploid blastocyst transfer, PGT-A, preimplantation genetic testing

\section{INTRODUCTION}

In the modern society, women tend to get married and have children later than the previous generations. Therefore, the number of advanced maternal age (AMA) patients performing in-vitro fertilization (IVF) is increasing ${ }^{1}$. However, women fertility rate is inversely proportional to their age due to impairment of the ovarian reserve ${ }^{2}$ and increased abnormal oocytes ${ }^{3,4}$, which leads to the increase in embryonic aneuploidy rate. Aneuploidy is a common genetic abnormality in humans. Studies showed that the majority of embryo aneuploidy had a maternal ori$\operatorname{gin}^{5,6}$. This rate is higher as a woman gets older, and about $50 \%$ of the embryos from IVF treatment are aneuploidy ${ }^{7-9}$. Aneuploidy is the main reason causing implantation failure, early miscarriage, and pro- longed time to pregnancy in $\mathrm{IVF}^{4}$. Most of the aneuploidy occurs due to mitotic and meiotic error arisen in the preimplantation embryo stage ${ }^{10}$. In women over 35 years old, aneuploidy embryos may result in miscarriage, including natural pregnancy and IVF treatment cycles $^{9}$. Preimplantation genetic testing to detect aneuploidy of embryo is increasingly popular all over the world. Preimplantation genetic testing for aneuploidy (PGT-A) biopsy approache includes biopsy of polar bodies from the oocyte ${ }^{4,11}$, biopsy of blastomeres from cleavage-stage embryo, or trophectoderm (TE) cells from blastocyst embryo ${ }^{12,13}$. However, the biopsy of polar bodies only contains DNA of oocytes (maternal contributions) and does not represent the DNA in the embryonic status. There is evidence showing that the biopsy of blastomere is
Cite this article: Thi Bich Phuong L, Nguyen Thuc V, Thieu Quan P, Hoang Anh L, Quang Vinh D, Thi Thuong Huyen N. Selecting euploid embryo for transfer by preimplantation genetic testing for aneuploidy improved clinical outcomes in patients with advanced maternal age. Biomed. Res. Ther.; 6(12):3541-3549. 
not only an invasive technique affecting the development and embryonic implantation potential ${ }^{12,14,15}$, but also logistically difficult and costly ${ }^{16}$. Nowadays, biopsy of TE cells is currently the most widely used approach accounting for IVF centers ${ }^{17-19}$. TE biopsy intends to remove only 5-6 cells from the trophectoderm. Blastocyst of biopsy is the least invasive technique and does not affect the embryonic development and implantation potential ${ }^{12}$.

Multiple pregnancies are the primary concern of IVF centers. During the last decades, the common practice of transferring more than one embryo into the uterus was used to increase the clinical pregnancy rate. Although many centers have reduced the number of transferred embryos to decrease multiple pregnancy rate, the twinning rate remains high because double embryo transfer is often performed in their treatment cycle. Many studies have reported that twin pregnancy affects reproductive health and the cost of care for the newborns ${ }^{20-22}$. Therefore, the choice of single embryo transfer with high implantation potential is the goal of most of IVF centers.

PGT-A is the technique to select euploid embryos with the best implantation potential. This technique has been applied to treat patients with an increased risk of having aneuploid embryos, such as those with advanced maternal age ${ }^{1,23}$, repeated implantation failure ${ }^{24}$, and recurrent miscarriage ${ }^{25-27}$. Up to date, PGT-A studies remain limited and have not been reported for the clinical outcomes in patients with advanced maternal age in Vietnam. Therefore, more evidence is needed for aneuploidy testing in this group of patients.

The purpose of our study was to assess the clinical outcomes following blastocyst biopsy and frozen euploid embryo transfer by using (PGT-A) for AMA patients in Vietnam.

\section{MATERIALS - METHODS}

\section{Patient selection and study design}

This is a retrospective cohort study. The data were obtained from 493 women (35 to 45 years old) from March 2017 to March 2019 at IVFMD (My Duc Hospital, Vietnam). This study was approved by the Reproductive Health and the Ethical Board of My Duc Hospital. The individual information was coded to ensure patient privacy. Exclusion criteria were as follows: in-vitro maturation (IVM) cycles, IUI change to ICSI cycles, patients with repeated implantation failure, recurrent miscarriage, and uterine abnormal. $\mathrm{Pa}-$ tients were divided into two groups: PGT-A (244 patients) and non-PGT-A (249 patients).

\section{Sperm preparation}

Both frozen and fresh semen samples were prepared by discontinuous density gradient centrifugation. This method helped to separate motile spermatozoa from seminal plasma. Two layers were formed with a $40 \%$ density top layer and an $80 \%$ density lower layer. The centrifugation helped motile spermatozoa swim through the gradient materials to form a soft pellet at the bottom of the tube. After that, the soft pellet was collected and washed to be used for ICSI ${ }^{28}$.

\section{Ovarian stimulation and Oocyte Retrieval}

The ovarian stimulation was carried out with a GnRH Antagonist protocol and ovulation is triggered by hCG or agonist injection. Follicle development was followed by ultrasound, and checked for estradiol and progesterone levels. Oocyte retrieval was done at 36 hours after hCG or agonist injection when at least two follicles reached $14 \mathrm{~mm}$. Upon retrieval, oocyte cumulus complexes were rinsed and cultured in Global Total for Fertilization medium (Life Global - Canada), supplemented with bicarbonate buffer, lactate and pyruvate, at $37^{\circ} \mathrm{C}, 6 \% \mathrm{CO}_{2}$ and $5 \% \mathrm{O}_{2}$ in the incubator. After that, the denudation of cumulus cells surrounding the oocytes was performed by using hyaluronidase (Origio- Denmark) and mechanical pipetting. Only matured oocytes (Metaphase II) were injected.

\section{Embryo culture}

Intracytoplasmic sperm injection (ICSI) was performed on the matured oocytes approximately 39 to 41 hours after hCG or agonist injection. Following the fertilization, embryos were placed in the Benchtop (G310, K-system, Denmark) incubator at $37^{\circ} \mathrm{C}$ with $\mathrm{CO}_{2}$ and $5 \% \mathrm{O}_{2}$.

\section{Fertilization and cleavage-stage embryo evaluation}

Fertilization analysis was assessed at 16-18 hours after ICSI. On day 3, the cleavage-stage embryos were evaluated base on the number of blastomeres, the size of blastomeres and the embryo fragmentation according to embryo assessment guidelines at IVFMD.

\section{Blastocyst evaluation}

The blastocyst was evaluated at 112 to 116 hours (on day 5) after ICSI, according to embryo assessment guidelines at IVFMD (based on Alpha Scoring System, 2011 $)^{29}$. Embryo quality was evaluated by morphology under the inverted microscope (Zeizz, Germany). The evaluation process was based on the de- 
gree of expansion, the number of cells and cell compaction of the inner cell mass (ICM), and the trophectoderm of the blastocyst. The high-quality embryos (grade 1 and grade 2) were classified with blastocoel filling greater than half the volume of the embryo, the ICM with tightly packed/ loosely grouped cells and the trophectoderm with cells forming cohesive epithelium or few cells forming lose epithelium (Figure 1a, b). The poor-quality embryos (grade 3) were classified with any other expansion degrees, the ICM with very few cells or degradation, and the trophectoderm with very few large cells or degradation (Figure 1 c). The high-quality embryos were prioritized for biopsy, vitrification, or transferring while the poor-quality embryos were not prioritized for biopsy or freeze.

\section{Biopsy of blastocyst}

The selection of embryos for biopsy follows the consensus at IVFMD (based on Alpha Scoring System, 2011 ${ }^{29}$. Biopsy samples contained 5-6 TE cells (Figure 2). The TE cells were washed in phosphatebuffered saline solution (PBS-Merk, Germany) and then stored in the microcentrifuge tubes containing $2 \mu \mathrm{l}$ PBS and were genetically analyzed at the genetic analysis laboratory (Tan Son Nhat Hospital, 2 Pho Quang Street, 2 Ward, Tan Binh District, Ho Chi Minh city).

\section{Embryo freezing, warming and transfer}

After blastocyst biopsy, the embryo was frozen using Kuwayama protocol ${ }^{30}$ with Vitrification kit (Cryotech, Japan), and was individually loaded onto carrier tool based on IVFMD's laboratory routine standardization. When genetic testing results were available, only the euploid embryo was chosen for transfer in the first of the frozen embryo transfer (FET) cycle. The embryo was thawed and morphology was assessed, hatching was assisted, and embryo was transferred with a specialized catheter under ultrasonographic guidance. After the thawing procedure, the thawed embryo morphology was assessed before it was transferred to patients. If the embryo showed degradation cells, it depended on the number of degrading cells; we decided to transfer this embryo or announced the patient to thaw another embryo. In this study, all thawed embryo could be transferred to the patient without having to thaw another. In FET cycle, the patients were transferred with one or two embryos, which is dependent on the patient's decision.

\section{Clinical outcome assessment}

The primary outcome was the ongoing pregnancy rate in the first frozen embryo transfer cycle of both groups. The ongoing pregnancy rate was defined as the percentage of embryos transferred that produced an implanted embryo and had the embryocardia under ultrasound up to week 12 of pregnancy ${ }^{31}$. The ongoing pregnancy rate was compared with the group of patients who only performed blastocyst transfer (nonPGT-A group). Other outcomes, such as the average number of transferred embryos, clinical pregnancy rate, implantation rate, miscarriage rate and multiple pregnancy rate were also compared between the two groups.

\section{Statistical analysis}

The baseline characteristics of the study population were described by descriptive statistics. For the study outcomes, histogram and Shapiro test were used to check for normal distribution and continuous variables. If the variables have a normal distribution, the data were presented as mean, standard deviation and compared by a Student $t$-test. If the variables were not normally distributed, the data were presented as median and quartile, non-parametric tests were used to check for differences between groups. For the category, we used percentages between the two branches and compared them with Pearson's chi-square test or Fisher's exact test if they were appropriate. All tests were two-tailed tests, $p$-values of less than 0.05 $(p<0.05)$ were considered as statistically significant. Values were expressed as mean \pm standard deviation (SD).

\section{RESULTS}

The baseline characteristics and ovarian stimulation results were showed in Table 1. Overall baseline characteristics and ovarian stimulation data including age, BMI, AMH level, duration of infertility, days of stimulation and total FSH were not significantly different between the two groups ( $p>0.05)$. Since the primary patient's characteristics were similar between two groups (Table 1), the consequent outcomes would be more objectivity and reliability.

The total of 493 patients underwent this study. There was a total of 7614 retrieved oocytes with $6258 \mathrm{ma}$ ture oocytes, which were performed ICSI. The number of fertilized oocytes were 5344, with fertilization rate reached $85.4 \%$. A total of 3017 blastocysts with blastocyst rate reached $48.1 \%$. The detailed parameters of each group were showed in Table 2. 


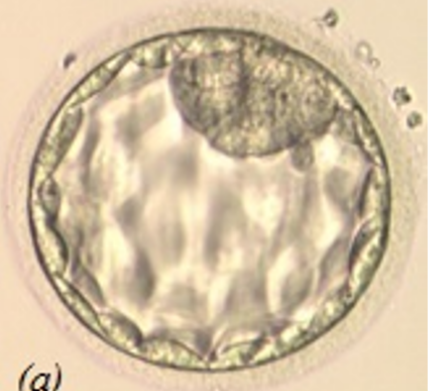

(a)
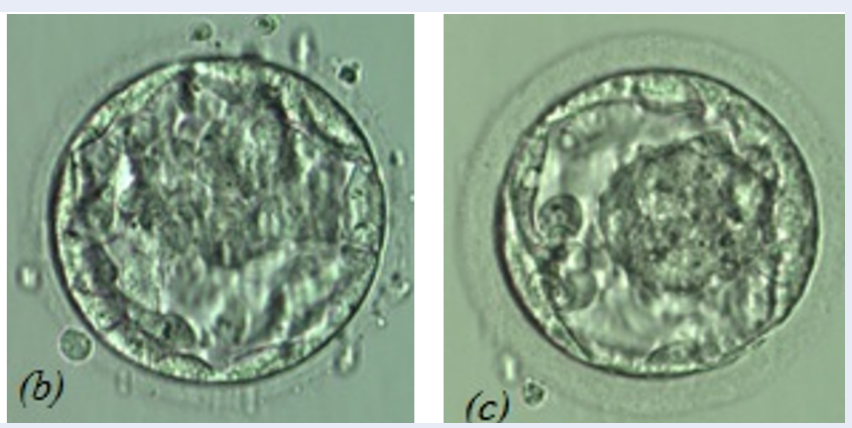

Figure 1: Day-5 embryos (20X magnification). (a) Grade 1 ; (b) Grade 2; (c) Grade 3.

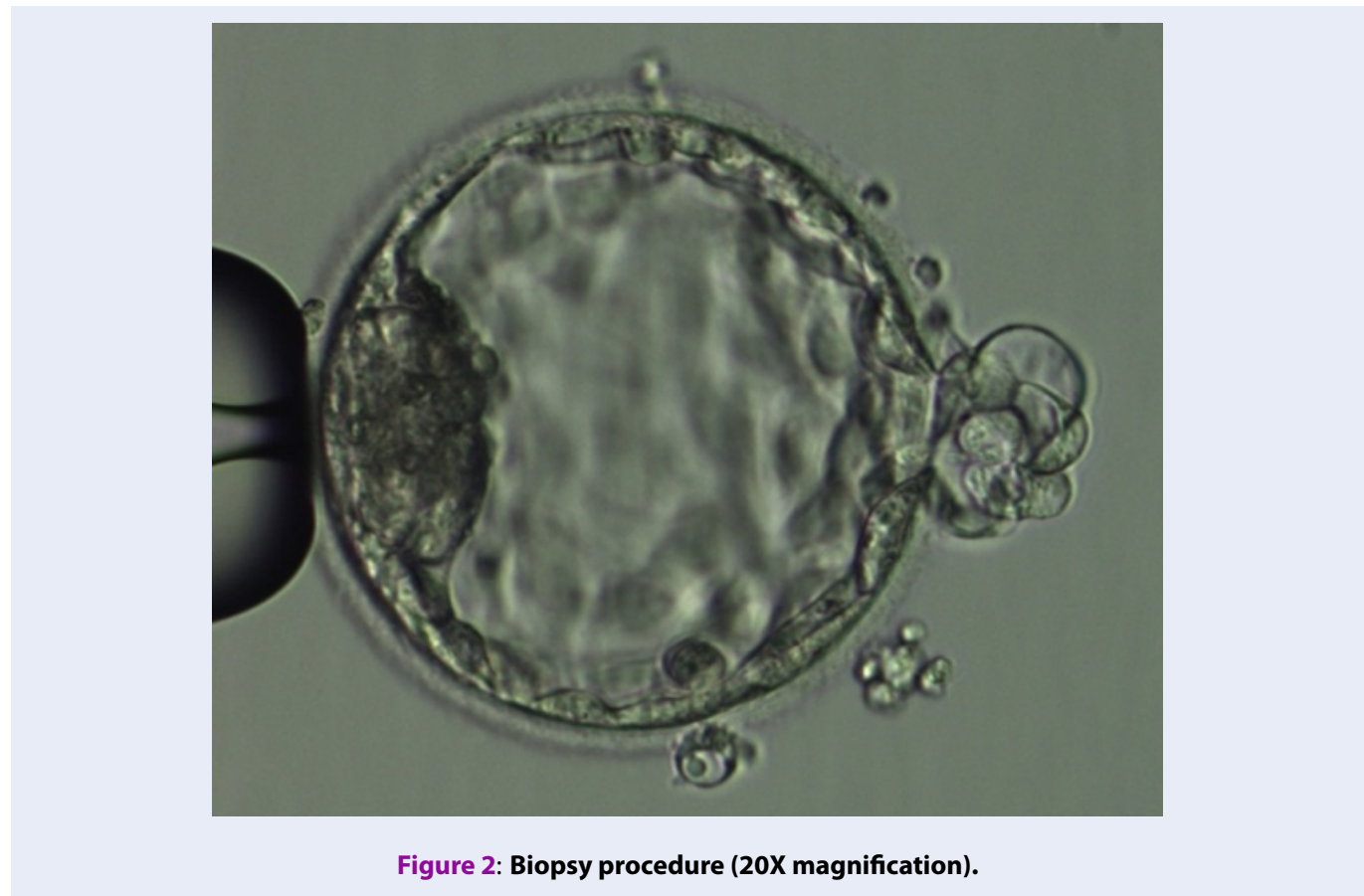

PGT-A group showed a similar average number of retrieved oocytes $(16.0 \pm 8.3$ vs. $14.9 \pm 4.5$ oocytes, $\mathrm{p}$ $=0.61)$ as compared to non-PGT-A group. PGT-A group showed higher average number of MII oocytes (13.4 \pm 7.1 vs. $12.0 \pm 4.1$ oocytes, $\mathrm{p}=0.008)$, fertilized oocytes $(11.8 \pm 6.1$ vs. $9.9 \pm 3.7$ oocytes, $\mathrm{p}<$ $0.001)$ and $2 \mathrm{PN}$ rate $(78.1 \pm 20.0$ vs. $74.3 \pm 19.1 \%$, $\mathrm{p}=0.03$ ) compared to non-PGT-A group. However, the blastocyst rate and number of good quality blastocyst embryos in the PGT-A group were lower than the non-PGT-A group $(48.1 \pm 24.1$ vs. $55.5 \pm 20.3 \%$, p < $0.001 ; 3.0 \pm 2.8$ vs. $4.2 \pm 2.8$ embryos, $\mathrm{p}<0.001$, respectively), while two groups showed no statistically significant differences in the average number of blastocyst embryos $(6.0 \pm 4.1$ vs. $6.6 \pm 3.2$ embryos, $\mathrm{p}=$ 0.108).
In PGT-A group, the mean of biopsy blastocyst was $3.4 \pm 1.9$ blastocyst embryos. From all patients, a total of 816 blastocyst embryos were biopsied and genetically analyzed. The euploid embryos had the highest rate $(59.9 \%)$, followed by aneuploid embryo rate (38.6\%), and finally mosaic embryo rate (1.5\%). In the group of the aneuploid embryo (489 embryos), there were 73 complex embryos (23.2\%), 92 trisomy embryos (29.2\%), 100 monosomy embryos (31.7\%) and 50 structurally abnormal embryos (15.9\%). These results showed that the percentage of the aneuploid embryo was higher in AMA patients, approximately accounting for half of biopsied embryo (Table 3 ).

The ongoing pregnancy rate of PGT-A group was significantly higher than the non-PGTA group (43.9\% vs. $32.1 \%, \mathrm{p}=0.01)$. The PGT-A group also showed 
Table 1: The baseline characteristics and ovarian stimulation results

\begin{tabular}{|c|c|c|c|}
\hline & $\begin{array}{l}\text { PGT-A } \\
(\mathrm{N}=244)\end{array}$ & $\begin{array}{l}\text { non-PGT-A } \\
(\mathrm{N}=249)\end{array}$ & P-value \\
\hline \multicolumn{4}{|l|}{ The baseline characteristics } \\
\hline Age (years) & $38.1 \pm 2.7$ & $38.4 \pm 0.6$ & 0.128 \\
\hline BMI $\left(\mathrm{kg} / \mathrm{m}^{2}\right)$ & $21.7 \pm 2.3$ & $21.8 \pm 2.6$ & 0.657 \\
\hline AMH level (ng/ml) & $4.1 \pm 3.0$ & $4.0 \pm 3.1$ & 0.593 \\
\hline Duration of infertility (years) & $6.0 \pm 4.2$ & $6.5 \pm 4.4$ & 0.168 \\
\hline $\begin{array}{l}\text { Estradiol level on hCG day } \\
(\mathrm{pmol} / \mathrm{L})\end{array}$ & $8985.3 \pm 10861.7$ & $7126.4 \pm 6253.9$ & 0.03 \\
\hline $\begin{array}{l}\text { Progesterone level on hCG } \\
\text { day (pmol/L) }\end{array}$ & $1.8 \pm 4.1$ & $1.6 \pm 3.5$ & 0.633 \\
\hline $\begin{array}{l}\text { Total days of stimulation } \\
\text { (days) }\end{array}$ & $8.9 \pm 1.3$ & $15.8 \pm 113.8$ & 0.34 \\
\hline Total of FSH dose (IU) & $2476.6 \pm 533.6$ & $2379.6 \pm 692.6$ & 0.088 \\
\hline
\end{tabular}

Table 2: Embyonic outcome data

\begin{tabular}{llll}
\hline & $\begin{array}{l}\text { PGT-A } \\
\text { (N=244) }\end{array}$ & $\begin{array}{l}\text { non-PGT-A } \\
(\mathrm{N}=249)\end{array}$ & P - value \\
\hline Number of retrieved oocytes & $16.0 \pm 8.3$ & $14.9 \pm 4.5$ & 0.061 \\
Number of MII oocytes & $13.4 \pm 7.1$ & $12.0 \pm 4.1$ & 0.008 \\
Number of fertilized oocytes & $11.8 \pm 6.1$ & $9.9 \pm 3.7$ & $<0.001$ \\
2PN rate & $78.1 \pm 20.0$ & $74.3 \pm 19.1$ & 0.03 \\
Blastocyst rate & $48.1 \pm 24.1$ & $55.5 \pm 20.3$ & $<0.001$ \\
Number of blastocyst & $6.0 \pm 4.1$ & $6.6 \pm 3.2$ & 0.108 \\
Number of good quality blastocyst & $3.0 \pm 2.8$ & $4.2 \pm 2.8$ & $<0.001$ \\
Number of blastocyst for PGT-A & $3.4 \pm 1.9$ & - & - \\
\hline
\end{tabular}

Table 3: Genetic testing results of the patients ( $N=816$ embryos)

\begin{tabular}{ll}
\hline & PGT-A (N=816) \\
\hline Euploidy - n (\%) & $489(59.9)$ \\
Mosaic - n (\%) & $12(1.5)$ \\
Aneuploidy - n (\%) & $315(38.6)$ \\
Complexs & $73(23.2)$ \\
Trisomy & $92(29.2)$ \\
Monosomy & $100(31.7)$ \\
Structural abnormality & $50(15.9)$ \\
\hline
\end{tabular}




\begin{tabular}{lccc}
\hline Table 4: Clinical outcome data & & \\
\hline Parameters & $\begin{array}{c}\text { PGT-A } \\
(\mathrm{N}=244)\end{array}$ & $\begin{array}{r}\text { non-PGT-A } \\
(\mathrm{N}=249)\end{array}$ & P - value \\
\hline Number of embryo transferred & $1.3 \pm 0.4$ & $2.0 \pm 0.4$ & $<0.001$ \\
-hCG positive rate & $61.5 \%$ & $43.0 \%$ & $<0.001$ \\
Clinical pregnancy rate & $54.9 \%$ & $38.6 \%$ & $<0.001$ \\
Multiple pregnancy rate & $5.7 \%$ & $12.0 \%$ & $<0.001$ \\
Implantation rate & $49.3 \%$ & $40.2 \%$ & $<0.001$ \\
Miscarriage rate & $11.1 \%$ & $6.4 \%$ & 0.096 \\
Ongoing pregnancy rate & $43.9 \%$ & $32.1 \%$ & 0.01 \\
Live birth rate & $38.5 \%$ & $30.9 \%$ & 0.093 \\
Birth Weight $($ gram $)-(\mathrm{sd})$ & $2918 \pm 538$ & $3027 \pm 621$ & 0.082 \\
\hline
\end{tabular}

higher average number of the -hCG positive rate, implantation rate and clinical pregnancy rate than nonPGT-A group $(61.5 \%$ vs. $43.0 \%, 49.3 \%$ vs. $40.2 \%$, $54.49 \%$ vs. $38.6 \%, \mathrm{p}<0.001$, respectively). In contrast, the mean number of embryos transferred and the multiple pregnancy rate in the PGT-A group was significantly lower than the non-PGT-A group (1.3 vs. 2.0 embryos, $5.7 \%$ vs. $12.0 \%, \mathrm{p}<0.001$, respectively). There was no statistically significant difference in the miscarriage rate between the two groups (11.1\% vs. $6.4 \%, \mathrm{p}=0.096)$. The live birth rate of PGTA group was higher than non-PGT-A but not statistically different $(38.5 \%$ vs. $30.9 \%, \mathrm{p}=0.093)$. The result showed that the birth weight was similar between the two groups (2918 g vs. $3027 \mathrm{~g}, \mathrm{p}=0.082$ ) (Table 4 ).

\section{DISCUSSION}

The goal of the PGT-A was to select single euploid embryo to transfer to IVF patients to increase the chance of pregnancy and having a healthy baby. The aneuploidy rate was increased in patients, who took IVF treatment at advanced maternal age ${ }^{9,32,33}$. The probability of successful development and implantation at the early stage of the embryo depends on the genetic status. Subsequent errors in the genetic of the embryos can lead to embryonic mortality. Aneuploidy (monosomy and trisomy) is the most common type of abnormal chromosome in humans. The aneuploid embryos could not develop in the uterus after they were transferred; therefore, the frozen embryo transfer cycle using these aneuploid embryos would significantly decrease the pregnancy rate of the patients.

For this reason, euploidy embryo selection for transfer can improve implantation rate as well as the ongoing pregnancy rate of advanced maternal age. The study of Minasi (2016) showed that mean maternal age in the euploidy was younger than aneuploidy group ${ }^{34}$. Moreover, this research was that emphasized the aneuploidy rate rises approximately $10 \%$ per year of female age. Therefore, it is necessary to use appropriate technique for identifying euploidy without reducing the embryo implantation potential.

Our research compared the clinical outcomes between AMA patients with or without transferring the euploid embryo selected by PGT-A. The ongoing pregnancy rate of PGT-A group was significantly higher than non-PGT-A group $(43.9 \%$ vs. $32.1 \%$, $\mathrm{p}=0.01$ ). Moreover, the mean number of embryos transferred and the multiple pregnancy rate of the PGT-A group was lower than non-PGT-A group (1.3 vs. 2.0 embryos, $\mathrm{p}<0.001 ; 5.7 \%$ vs. $12 \%$, $\mathrm{p}<0.001$, respectively).

A multicenter, randomized clinical trial by Rubio et al., 2017 assessed clinical outcomes in advanced maternal age between 38 and 41 years with euploidy transferred showed that the miscarriage rate of PGTA group exhibited significantly lower than the control group $(2.7 \%$ vs. $39.0 \%, \mathrm{p}<0.001)$. The pregnancy rate at the first transfer attempt was higher $(52.9 \%$ vs. $24.2 \%, \mathrm{p}<0.001)$, lower the number of transferred embryos (1.3 vs. $1.8, \mathrm{p}<0.0001)$ and the time to achieve a live birth of PGT-A group were also lower compared to the non PGT-A group (7.7 weeks vs. 14.9 weeks) ${ }^{1}$.

Similar to our results, the study of Schoolcraft $v s$. Katz-Jaffe (2013) determined that the ongoing pregnancy rate of the euploid blastocyst transferred group was higher than the control group (60.0\% vs. $43.8 \%$, $\mathrm{p}<0.05)^{6}$. The report of Harton (2013) indicated that the implantation rate and the ongoing pregnancy 
rate were constant in patients of 35 to 42 years old, who performed PGT-A and single euploid embryo $\operatorname{transfer}^{35}$. Recently, a publication of Taiwanese researchers showed that the AMA patients with ICSI/ PGT-A and the euploidy transfer had significantly higher live birth rate than non-PGT-A group ${ }^{23}$.

Chang et al. (2019) compared the women who underwent PGT-A with a single euploid frozen embryo transfer group versus the women who underwent a multiple unscreened embryo transfer of fresh embryo cycles in women $\geq 43$ years. This study outcomes showed that the study group had significantly higher implantation rate $(56.9 \%$ vs. $13.8 \%$, OR 8.9 [95\% CI 4.9-16.3]) and ongoing pregnancy rate (50.0\% vs. 6.9\%, OR 14.3 [95\% CI 7.3-28.0]), and lower early miscarriage pregnancy rate $(18.3 \%$ vs. $46.2 \%$, OR 0.25, [95\% CI 0.11-0.57]) and clinical miscarriage pregnancy rate $(12.1 \%$ vs. $50.0 \%$, OR 0.16 [95\% CI 0.06-0.47]), compared to control group ${ }^{36}$.

Another study of Verpoest W (2018) demonstrated that live birth rate between PGT-A and non-PGTA groups were similar (24\%; 95\% CI: -7.60- 9.18\%), while the PGT-A group have lower miscarriage rate than the control group. However, the sample size of PGT-A group was small, thus, the number of euploidy transferred in PGT-A group was higher (41\% double embryo transfer) leading to high multiple pregnancy rate and miscarriage rate ${ }^{3}$.

Besides, Shelby A. Neal (2018) compared the costeffective and clinical outcomes of patients with or without PGT-A ${ }^{37}$. Comparing the cost-effective outcomes on patient's age, excluded patients who have only one blastocyst, the patients $>37$ years of age saved more treatment cost than patients $<35$ years of age. Furthermore, this study showed that the cumulative live births of PGT-A and control groups were identical but PGT-A reduced the time in treatments up to four months, and decreased the risk of embryo transfer failure and pregnancy loss ${ }^{37}$.

The limitation of our study is that it was a retrospective cohort study, in which we did not actively select samples for the study. We collected data on treated outcomes of the patient in IVFMD, My Duc Hospital, Vietnam from March 2017 to March 2019.

\section{CONCLUSIONS}

The transfer of euploid embryo improved the clinical outcomes of advanced maternal age. Specifically, our study showed that the euploid embryo selection by PGT-A increased clinical pregnancy rate, implantation rate, ongoing pregnancy rate and decreased multiple pregnancy rate due to the reduced number of embryo transfers. Therefore, PGT-A can be consulted to women with advanced maternal age, who carried out IVF at My Duc Hospital. However, this was a retrospective study, a better well-designed study with a more considerable sample size needs to be considered in the future.

\section{ABBREVIATIONS}

PGT-A: Preimplantation Genetic Testing- Aneuploidy

IVF: In- vitro fertilization

ICSI: Intracytoplasmic sperm injection

BMI: Body mass index

AMH: Antimuller hormone

FSH: Follical stimulating hormone

IVM: In-vitro Maturation

IUI: Intrauterine insemination

\section{CONFLICT OF INTEREST}

The authors declare that they have not conflicted of interests.

\section{AUTHORS' CONTRIBUTIONS}

LTBP wrote the manuscript. VNT and LHA revised the manuscript. DQV planned and designed the experiments. PTQ collected and analysed the data. NTTH supervised the study and finalized the manuscript. All authors read and confirmed the publication of the article.

\section{ACKNOWLEDGMENTS}

This study was performed at IVFMD-My Duc Hospital and IVFMD PN-My Duc Phu Nhuan Hospital. The authors acknowledge Directors to support the data and devices for this study. We are also thankful to our colleague from IVFMD PN who positively assisted in completing this study.

\section{REFERENCES}

1. Rubio C, Bellver J, Rodrigo L, Castillón G, Guillén A, Vidal $C$, et al. In vitro fertilization with preimplantation genetic diagnosis for aneuploidies in advanced maternal age: a randomized, controlled study. Fertility and Sterility. 2017;107(5):1122-9. PMID: 28433371. Available from: 10.1016/j.fertnstert.2017.03.011.

2. Hassold T, Hunt P. Maternal age and chromosomally abnormal pregnancies: what we know and what we wish we knew. Current Opinion in Pediatrics. 2009;21(6):703-8. PMID: 19881348. Available from: 10.1097/MOP.0b013e328332c6ab.

3. Fragouli E, Alfarawati S, Spath K, Jaroudi S, Sarasa J, Enciso M, et al. The origin and impact of embryonic aneuploidy. Human Genetics. 2013;132(9):1001-13. PMID: 23620267. Available from: 10.1007/s00439-013-1309-0.

4. Verpoest W, Staessen C, Bossuyt PM, Goossens V, Altarescu G, Bonduelle $M$, et al. Preimplantation genetic testing for aneuploidy by microarray analysis of polar bodies in advanced maternal age: a randomized clinical trial. Human Reproduction (Oxford, England). 2018;33(9):1767-76. PMID: 30085138. Available from: 10.1093/humrep/dey262. 
5. Webster A, Schuh M. Mechanisms of Aneuploidy in Human Eggs. Trends in Cell Biology. 2017;27(1):55-68. PMID: 27773484. Available from: 10.1016/j.tcb.2016.09.002.

6. McCallie BR, Parks JC, Trahan GD, Jones KL, Coate BD, Griffin DK, et al. Compromised global embryonic transcriptome associated with advanced maternal age. Journal of Assisted Reproduction and Genetics. 2019;36(5):915-24. PMID: 31025158. Available from: 10.1007/s10815-019-01438-5.

7. Kuliev A, Cieslak J, Ilkevitch Y, Verlinsky Y. Chromosomal abnormalities in a series of 6,733 human oocytes in preimplantation diagnosis for age-related aneuploidies. Reproductive Biomedicine Online. 2003;6(1):54-9. PMID: 12626143. Available from: 10.1016/S1472-6483(10)62055-X.

8. Rabinowitz M, Ryan A, Gemelos G, Hill M, Baner J, Cinnioglu C, et al. Origins and rates of aneuploidy in human blastomeres. Fertility and Sterility. 2012;97(2):395-401. PMID: 22195772. Available from: 10.1016/j.fertnstert.2011.11.034.

9. Franasiak JM, Forman EJ, Hong KH, Werner MD, Upham KM, Treff NR, et al. The nature of aneuploidy with increasing age of the female partner: a review of 15,169 consecutive trophectoderm biopsies evaluated with comprehensive chromosomal screening. Fertility and Sterility. 2014;101(3). PMID: 24355045. Available from: 10.1016/j.fertnstert.2013.11.004.

10. Sermon K. Novel technologies emerging for preimplantation genetic diagnosis and preimplantation genetic testing for aneuploidy. Expert Review of Molecular Diagnostics. 2017;17(1):71-82. PMID: 27855520. Available from: 10.1080/ 14737159.2017.1262261.

11. Geraedts J, Collins J, Gianaroli L, Goossens V, Handyside A, Harper J, et al. What next for preimplantation genetic screening? A polar body approach! Human Reproduction (Oxford, England). 2010;25(3):575-7. PMID: 20031957. Available from: 10.1093/humrep/dep446.

12. Cimadomo D, Capalbo A, Ubaldi FM, Scarica C, Palagiano A, Canipari R. The Impact of Biopsy on Human Embryo Developmental Potential during Preimplantation Genetic Diagnosis. Biomed Res Int. 2016;2016. Available from: 10.1155/2016/ 7193075.

13. Homer HA. Preimplantation genetic testing for aneuploidy (PGT-A): the biology, the technology and the clinical outcomes. Australian and New Zealand Journal of Obstetrics and Gynaecology. 2019;59(2):317-24. PMID: 30811595. Available from: 10.1111/ajo.12960.

14. Scott RT, Upham KM, Forman EJ, Zhao T, Treff NR. Cleavagestage biopsy significantly impairs human embryonic implantation potential while blastocyst biopsy does not: a randomized and paired clinical trial. Fertility and Sterility. 2013;100(3):624-30. PMID: 23773313. Available from: 10. 1016/j.fertnstert.2013.04.039.

15. Scott RT, Upham KM, Forman EJ, Hong KH, Scott KL, Taylor $D$, et al. Blastocyst biopsy with comprehensive chromosome screening and fresh embryo transfer significantly increases in vitro fertilization implantation and delivery rates: a randomized controlled trial. Fertility and Sterility. 2013;100(3):697703. PMID: 23731996. Available from: 10.1016/j.fertnstert. 2013.04.035

16. Griffin DK, Ogur C. Chromosomal analysis in IVF: just how useful is it? Reproduction (Cambridge, England). 2018;156(1):2950. PMID: 29945889. Available from: 10.1530/REP-17-0683.

17. He H, Jing S, Lu CF, Tan YQ, Luo KL, Zhang SP, et al. Neonatal outcomes of live births after blastocyst biopsy in preimplantation genetic testing cycles: a follow-up of 1,721 children. Fertility and Sterility. 2019;112(1):82-8. PMID: 31056308. Available from: 10.1016/j.fertnstert.2019.03.006.

18. Victor AR, Griffin DK, Brake AJ, Tyndall JC, Murphy AE, Lepkowsky LT, et al. Assessment of aneuploidy concordance between clinical trophectoderm biopsy and blastocyst. Human Reproduction (Oxford, England). 2019;34(1):181-92. PMID: 30418565. Available from: 10.1093/humrep/dey327.

19. Fragouli E, Alfarawati S, Spath K, Babariya D, Tarozzi N, Borini $A$, et al. Analysis of implantation and ongoing pregnancy rates following the transfer of mosaic diploid-aneuploid blasto- cysts. Human Genetics. 2017;136(7):805-19. PMID: 28393271. Available from: 10.1007/s00439-017-1797-4.

20. Lemos EV, Zhang D, Voorhis BJV, Hu XH. Healthcare expenses associated with multiple vs singleton pregnancies in the United States. American Journal of Obstetrics and Gynecology. 2013;209(6). PMID: 24238479. Available from: 10.1016/j.ajog.2013.10.005.

21. Pinborg A, Loft A, Schmidt L, Andersen AN. Morbidity in a Danish national cohort of 472 IVF/ICSI twins, 1132 nonIVF/ICSI twins and 634 IVF/ICSI singletons: health-related and social implications for the children and their families. Human Reproduction (Oxford, England). 2003;18(6):1234-43. PMID: 12773452. Available from: 10.1093/humrep/deg257.

22. Sazonova A, Källen K, Thurin-Kjellberg A, Wennerholm UB, Bergh $C$. Neonatal and maternal outcomes comparing women undergoing two in vitro fertilization (IVF) singleton pregnancies and women undergoing one IVF twin pregnancy. Fertility and Sterility. 2013;99(3):731-7. PMID: 23219009. Available from: 10.1016/j.fertnstert.2012.11.023.

23. Lee $\mathrm{Cl}, \mathrm{Wu} \mathrm{CH}$, Pai YP, Chang YJ, Chen $\mathrm{Cl}$, Lee $\mathrm{TH}$, et al. Performance of preimplantation genetic testing for aneuploidy in IVF cycles for patients with advanced maternal age, repeat implantation failure, and idiopathic recurrent miscarriage. Taiwanese Journal of Obstetrics \{\&amp; \}amp; Gynecology. 2019;58(2):239-43. PMID: 30910146. Available from: 10.1016/j.tjog.2019.01.013.

24. Greco E, Bono S, Ruberti A, Lobascio AM, Greco P, Biricik A. Comparative genomic hybridization selection of blastocysts for repeated Implantation Failure Treatment: A Pilot Study. Biomed Res Int. 2014;2014. Available from: 10.1155/2014/ 457913.

25. Murugappan G, Ohno MS, Lathi RB. Cost-effectiveness analysis of preimplantation genetic screening and in vitro fertilization versus expectant management in patients with unexplained recurrent pregnancy loss. Fertility and Sterility. 2015;103(5):1215-20. PMID: 25772770. Available from: 10. 1016/j.fertnstert.2015.02.012.

26. Hodes-Wertz B, Grifo J, Ghadir S, Kaplan B, Laskin CA, Glassner $\mathrm{M}$, et al. Idiopathic recurrent miscarriage is caused mostly by aneuploid embryos. Fertility and Sterility. 2012;98(3):675-80. PMID: 22683012. Available from: 10.1016/j.fertnstert.2012.05. 025.

27. Hachem HE, Crepaux V, May-Panloup P, Descamps P, Legendre G, Bouet PE. Recurrent pregnancy loss: current perspectives. International Journal of Women\{\&amp;\}\{\#\}×0027; Health. 2017;9:331-45. PMID: 28553146. Available from: 10.2147/IJWH.S100817.

28. Organization WH. Examination and processing of human semen. World Health [Internet]. 2010;Edition, F(10):286. Available from: http://whqlibdoc.who.int/publications/2010/9789 241547789_eng.pdf.

29. Medicine ASIR, Embryology ESIG. Istanbul consensus workshop on embryo assessment: proceedings of an expert meeting. Reproductive Biomedicine Online. 2011;22(6):632-46. PMID: 21481639. Available from: 10.1016/j.rbmo.2011.02.001.

30. Kuwayama M. Highly efficient vitrification for cryopreservation of human oocytes and embryos: the Cryotop method. Theriogenology. 2007;67(1):73-80. PMID: 17055564. Available from: 10.1016/j.theriogenology.2006.09.014.

31. Yi Y, Lu G, Ouyang Y, lin G, Gong F, Li X. A logistic model to predict early pregnancy loss following in vitro fertilization based on 2601 infertility patients. Reproductive Biology and Endocrinology. 2016;14(1):15. PMID: 27036944. Available from: 10.1186/s12958-016-0147-z.

32. Liu J, Wang W, Sun X, Liu L, Jin H, Li M, et al. DNA microarray reveals that high proportions of human blastocysts from women of advanced maternal age are aneuploid and mosaic. Biology of Reproduction. 2012;87(6):148. PMID: 23136294. Available from: 10.1095/biolreprod.112.103192.

33. Fragouli E, Alfarawati S, Daphnis DD, Goodall NN, Mania A, Griffiths T, et al. Cytogenetic analysis of human blastocysts 
with the use of FISH, CGH and aCGH: scientific data and technical evaluation. Human Reproduction (Oxford, England) 2011;26(2):480-90. PMID: 21147821. Available from: 10.1093/ humrep/deq344.

34. Minasi MG, Colasante A, Riccio T, Ruberti A, Casciani V, Scarselli $F$, et al. Correlation between aneuploidy, standard morphology evaluation and morphokinetic development in 1730 biopsied blastocysts: a consecutive case series study. Human Reproduction (Oxford, England). 2016;31(10):224554. PMID: 27591227. Available from: 10.1093/humrep/dew183.

35. Harton GL, Munné S, Surrey M, Grifo J, Kaplan B, McCulloh DH, et al. Diminished effect of maternal age on implantation after preimplantation genetic diagnosis with array comparative genomic hybridization. Fertility and Sterility. 2013;100(6):1695-
703. PMID: 24034939. Available from: 10.1016/j.fertnstert. 2013.07.2002.

36. Chang S, Nazem TG, Sekhon LH, Mukherjee T, Lee JA, Copperman AB. Transfer of a single genetically screened embryo in women \&amp;gt;43 results in significantly higher pregnancy rates and lower pregnancy loss rates than transfer of multiple unscreened embryos. Fertility and Sterility. 2019;111(4):e35. Available from: 10.1016/j.fertnstert.2019.02.088.

37. Neal SA, Morin SJ, Franasiak JM, Goodman LR, Juneau CR, Forman EJ, et al. Preimplantation genetic testing for aneuploidy is cost-effective, shortens treatment time, and reduces the risk of failed embryo transfer and clinical miscarriage. Fertility and Sterility. 2018;110(5):896-904. PMID: 30316435. Available from: 10.1016/j.fertnstert.2018.06.021. 